\section{Screening for cystic fibrosis by analysis of serum protein in faeces}

Recently we reported the preliminary results of a 3-year study into the feasibility of screening for cystic fibrosis (CF) by the electroimmunoassay of albumin and the protease inhibitors in meconium (Ryley et al., 1975). The high number of falsepositive results obtained when estimating albumin $(0.5 \%$ of all specimens) could be much reduced if an albumin : $\alpha_{1}$-antitrypsin ratio was estimated. The ratio compared the concentration in meconium of a protein liable to proteolysis, albumin, with that of a protein resistant to proteolysis, $a_{1}$ antitrypsin, and may be regarded as an index of gut proteolysis. The ratio has a value of about 10 in the total absence of gut proteolytic activity. It was also found that both the albumin content and the ratio value were reduced in subsequent meconium specimens if the infant was healthy but maintained their original high values if the infant had CF. As further meconium specimens from the same child are not always available, it would be useful to know if faeces from healthy infants and infants with CF could be similarly differentiated.

\section{Methods and materials}

The children from whom faecal specimens were collected were divided into four categories.

Group I. 5 infants with $\mathrm{CF}$ whose meconium specimens gave a positive result with the meconium screening tests. CF was verified by the results of sweat chloride estimations and subsequent clinical development of the infants. Ages at time of stool collection varied between 1 and 6 months.

Group II. 4 infants with CF whose meconium gave a negative result with the meconium tests. CF was proved after they presented with clinical signs of the disease. Ages at time of stool collection were all approximately 4 months.

Group III. 10 infants free of CF but whose meconium specimens gave a positive result with the meconium screening tests. All had meconium albumin values of more than $50 \mathrm{mg} / \mathrm{g}$ dry weight; 7 had albumin : $\alpha_{1}$ antitrypsin ratio values of more than $2 \cdot 0$ and 9 of the 10 infants were considered to have been born preterm. Ages at time of collection of stools varied between 2 and 4 weeks.

Group IV. 39 infants free of CF but who had presented with outward clinical signs often associated with the disease, e.g. failure to gain weight, persistent chest infections etc., but were subsequently found to have normal sweat chloride levels. Records of the meco- nium screening tests for these infants were incomplete but in none was CF suspected at birth. Ages at time of collection of stools varied between 2 months and 3 years. 2 further infants passed faeces that gave positive test results over a short period of time and were considered separately.

All faecal specimens were frozen as soon as possible after collection, lyophilized, and stored at $-20^{\circ} \mathrm{C}$ until analysed. A 4\% extract of each specimen was prepared as previously described (Ryley et al., 1974) and the extract was analysed for albumin and $\alpha_{1}$-antitrypsin by electroimmunoassay in agarose with specific antisera (Ryley et al., 1974).

\section{Results}

The Table summarizes the results of the analysis of faeces from the 4 groups. Only one of the faecal specimens from infants with CF (groups I and II) contained $<2.0 \mathrm{mg} / \mathrm{g}$ dry weight; the albumin content was $1.2 \mathrm{mg}$ and the ratio value low at $1 \cdot 7$. The duodenum was intubated within 24 hours of the infant passing the faecal specimen and though tryptic activity was detected in the duodenal aspirate, it was tenfold less than the tryptic activity in aspirates from children with normal pancreatic function (C. A. Smalley, personal communication, 1975). Faeces were studied from 3 of the same infants with CF after pancreatin supplement had been given in their diet and in none was albumin detected, though the faecal $\alpha_{1}$ antitrypsin concentrations were unchanged. Albumin was not detectable in the specimens from group III infants, but in one specimen from a group IV infant the albumin content was $1.8 \mathrm{mg} / \mathrm{g}$ dry weight and the albumin : $\alpha_{1}$ antitrypsin ratio was 0.4 .

Over a short time 2 infants, not included in the Table, passed faeces that could be considered positive by these tests. One infant had inspissated milk syndrome. The impacted faecal specimen had an albumin content of $35 \mathrm{mg} / \mathrm{g}$ dry weight and a ratio value of $6 \cdot 5$, but within 2 weeks of removing the blockage the faecal albumin content had dropped to $<0 \cdot 1 \mathrm{mg} / \mathrm{g}$ dry weight. The other infant was a sib of a known CF child The meconium was heavily contaminated with blood making analysis by the usual methods impossible, but by using the correction factors based on haptoglobin content in meconium (Ryley et al., 1975) we concluded the protein content of meconium was normal. Followup studies of her faeces indicated a slow rise in the albumin : $\alpha_{1}$ antitrypsin ratio over a period of one month from 0.3 to $4 \cdot 1$. The ratio then dropped to zero and the infant, now one year old, is considered not to have CF. We subsequently learned that three sweat chloride estimations made over the 
TABLE

Albumin and $\alpha_{1}$-antitrypsin content of faeces from infants with cystic fibrosis $(C F)$ and from infants with no $C F$

\begin{tabular}{|c|c|c|c|c|c|c|c|}
\hline & \multirow{2}{*}{$\begin{array}{c}\text { No. of } \\
\text { specimens }\end{array}$} & \multicolumn{2}{|c|}{$\begin{array}{c}\text { Albumin } \\
\text { (mg/g dry weight) }\end{array}$} & \multicolumn{2}{|c|}{$\begin{array}{c}\alpha_{1} \text {-Antitrypsin } \\
\text { (mg/g dry weight) }\end{array}$} & \multicolumn{2}{|c|}{$\begin{array}{c}\text { Albumin : } \\
\alpha_{1-\text { antitrypsin ratio }}\end{array}$} \\
\hline & & Mean $\pm S D$ & $\begin{array}{l}\text { Limit of } \\
\text { determined } \\
\text { value }\end{array}$ & Mean $\pm S D$ & $\begin{array}{l}\text { Limit of } \\
\text { determined } \\
\text { value }\end{array}$ & Mean $\pm S D$ & $\begin{array}{l}\text { Limit of } \\
\text { determined } \\
\text { value }\end{array}$ \\
\hline $\begin{array}{l}\text { Infants with CF detected } \\
\text { on meconium screening } \\
\text { (group I) } \\
\text { Infants with CF not } \\
\text { detected on meconium } \\
\text { screening (group II) } \\
\text { Infants free of CF but } \\
\text { who had a positive } \\
\text { meconium screening } \\
\text { test (group III) } \\
\text { Infants free of CF but } \\
\text { who had similar clinical } \\
\text { symptomology } \\
\text { (group IV) }\end{array}$ & 4 & $\begin{array}{l}4 \cdot 7 \pm 1 \cdot 6 \\
7 \cdot 0 \pm 7 \cdot 2\end{array}$ & $\begin{array}{l}2 \cdot 0-6 \cdot 0 \\
1 \cdot 2-13 \cdot 0\end{array}$ & $\begin{array}{l}0 \cdot 9 \pm 0 \cdot 4 \\
1 \cdot 0 \pm 0 \cdot 2 \\
2 \cdot 0 \pm 1 \cdot 0 \\
2 \cdot 1 \pm 1 \cdot 2\end{array}$ & $\begin{array}{l}0 \cdot 3-3 \cdot 6 \\
0 \cdot 6-4 \cdot 6\end{array}$ & $\begin{array}{c}6 \cdot 7 \pm 3 \cdot 6 \\
6 \cdot 0 \pm 5 \cdot 0 \\
<0 \cdot 1 \\
<0 \cdot 1\end{array}$ & $\begin{array}{l}4 \cdot 7-13 \cdot 0 \\
1 \cdot 7-13 \cdot 0\end{array}$ \\
\hline
\end{tabular}

same month gave consecutive sweat chloride values of 98,98 , and $44 \mathrm{mEq} / 1$. Since then further sweat chloride estimations have been made, but in no instance did the chloride concentration exceed $30 \mathrm{mEq} / 1$.

\section{Discussion}

Analysis of faeces presents some problems not encountered with meconium analysis. For example, the serum protein content of faeces was 20 -fold less than in meconium. Furthermore, faeces are not sterile when passed and there is the possibility of bacterial proteases giving spurious results. The first difficulty was overcome by increasing the extract concentration from $1 \%$ to $4 \%$ which made it possible to analyse faecal extracts in the same system as was used for meconium screening. The other problem of intrinsic bacterial contamination was not so easily overcome. Specimens were frozen as soon as possible after collection, and negative results obtained on specimens known to have been left to stand for some time at room temperature were interpreted with caution.

The results indicate that certain infants with CF may be identified by analysis of their faeces. The successful differentiation of group I and group III infants by the faecal albumin : $a_{1}$ antitrypsin ratio shows the value of faecal analysis when meconium screening indicated possible pancreatic insufficiency of the type associated with CF. The results of the analysis of faeces from group II and group IV infants illustrate its usefulness in the diagnosis of the disease where clinical signs might have led the clinician to suspect the possibility of CF. The number of specimens analysed in this study was limited and an assessment has still to be made of influences other than loss of pancreatic function that may affect serum protein content, such as bacterial proteases and the increase of inflammatory exudate associated with diarrhoea. However, the results were sufficiently encouraging for us to include faecal analysis into the screening programme currently in progress in this laboratory.

\section{Summary}

Faecal specimens from 51 infants free of cystic fibrosis (CF) and from 9 infants with the disease were analysed for albumin and $\alpha_{1}$-antitrypsin content. Faeces from infants with no CF had a mean albumin content of less than $0.1 \mathrm{mg} / \mathrm{g}$ dry weight and a mean albumin : $\alpha_{1}$-antitrypsin ratio value of less than $0 \cdot 1$. Faeces from infants with CF had, with one exception, an albumin content of more than $2.0 \mathrm{mg} / \mathrm{g}$ dry weight and a ratio value greater than 3.0. It was subsequently found that the duodenal aspirate from the child with CF but whose faeces had a low albumin content and ratio value, had tryptic activity though at a much reduced level compared to the activity in aspirates from healthy infants.

We are grateful for the assistance of Mrs. L. Mercy and Mrs. J. Eady. The work was supported by grants from the Cystic Fibrosis Research Trust and the Medical Research Council. 
REFBRENCES

Ryley, H. C., Neale, L., Brogan, T. D., and Bray, P. T. (1974). Plasma proteins in meconium from normal infants and from babies with cystic fibrosis. Archives of Disease in Childhood, $49,901$.

Ryley, H. C., Neale, L. M., Brogan, T. D., and Bray, P. T. (1975). Screening for cystic fibrosis by analysis of meconium for albumin and protease inhibitors. Clinica Chimica Acta, 64, 117.

H. C. Ryley, ^ LynNe M. Neale, R. Prosser, and J. DODGE
From the Departments of Medical Microbiology and Child Health, Welsh National School of Medicine, Cardiff, and Cystic Fibrosis Screening Unit, Royal Gwent Hospital, Newport.

*Correspondence to Dr. H. C. Ryley, Department of Medical Microbiology, Welsh National School of Medicine, Heath Park, Cardiff CF4 4XN.

\section{Neonatal Society}

\section{Autumn Meeting held on 13 November 1975 at St. Thomas's Hospital, London}

\section{Communications}

High energy feeding in immature infants. O. G. Brooke and M. Ferrer (introduced by D. R. Harvey). Department of Paediatrics, St. Mary's Hospital, London.

Insulin as a growth factor of fetus and newborn: clinical and endocrinological study of 2 cases with 'transient' neonatal diabetes. T. Takeuchi (introduced by J. P. M. Tizard). The Yodogawa Christian Hospital, Osaka, Japan.

Effect of cigarette smoking in pregnancy on maternal weight gain and fetal growth. M. Abernethy, D. P. Davies, C. Hopkinson, and D. Williams. Department of Child Health, University Hospital of Wales, Cardiff, and MRC Epidemiology Unit, Cardiff.

Influence of maternal obesity on subcutaneous fat in the newborn. A. G. L. Whitelaw (introduced by A. P. Norman). Institute of Child Health, London, and Queen Charlotte's Maternity Hospital, London.

Heart-linked tachypnoea. D. H. Garrow (introduced by $M$. K. Hathorn). Amersham General Hospital, Amersham, Bucks.
Permeability of brain-blood barrier during fetal and perinatal life. M. Adinolfi. Paediatric Research Unit, Guy's Hospital Medical School, London.

Animal model of intraventricular haemorrhage. G. M. Durbin, K. M. Dziegielewska, C. A. N. Evans, D. H. Malinowska, E. O. R. Reynolds, M. L. Reynolds, N. R. Saunders, and J. S. Wigglesworth. Departments of Paediatrics and Physiology, University College Hospital and Medical School, and Department of Paediatrics and Neonatal Medicine, Hammersmith Hospital, London.

Controlled trial of continuous inflating pressure for hyaline membrane disease. G. M. Durbin, N. J. Hunter, N. McIntosh, E. O. R. Reynolds, and P. D. Wimberley. Department of Paediatrics, University College Hospital and Medical School, London.

Effect of narcotic and narcotic-antagonist drugs in newborn rabbit. L. V. Cooper, D. R. Harvey, and G. W. Stephen. Queen Charlotte's Maternity Hospital, London.

Simple and accurate indirect method of measuring by infrasound systolic and diastolic pressures in the newborn. P. Rolfe (introduced by J. P. M. Tizard). Department of Paediatrics, University of Oxford, John Radcliffe Hospital, Oxford. 